\title{
A new look at the classical Bertrand duopoly
}

DOI:

10.1016/j.geb.2017.12.010

\section{Document Version}

Accepted author manuscript

Link to publication record in Manchester Research Explorer

\section{Citation for published version (APA):}

Amir, R., \& Evstigneev, I. (2018). A new look at the classical Bertrand duopoly. Games and Economic Behavior, 109, 99-103. https://doi.org/10.1016/j.geb.2017.12.010

\section{Published in:}

Games and Economic Behavior

\section{Citing this paper}

Please note that where the full-text provided on Manchester Research Explorer is the Author Accepted Manuscript or Proof version this may differ from the final Published version. If citing, it is advised that you check and use the publisher's definitive version.

\section{General rights}

Copyright and moral rights for the publications made accessible in the Research Explorer are retained by the authors and/or other copyright owners and it is a condition of accessing publications that users recognise and abide by the legal requirements associated with these rights.

\section{Takedown policy}

If you believe that this document breaches copyright please refer to the University of Manchester's Takedown Procedures [http://man.ac.uk/04Y6Bo] or contact uml.scholarlycommunications@manchester.ac.uk providing relevant details, so we can investigate your claim.

\section{OPEN ACCESS}




\title{
A new look at the classical Bertrand duopoly
}

\author{
Rabah Amir* and Igor V. Evstigneev**
}

\begin{abstract}
The paper provides necessary and sufficient conditions for the uniqueness of pure-strategy Nash equilibrium in the standard Bertrand duopoly with a homogeneous product. The main condition is elementary, easy to interpret, and nests all known sufficient conditions in the literature.
\end{abstract}

JEL codes: C72, L10.

Keywords: Price competition, uniqueness of Nash equilibrium, weakly dominated strategy, non-monotonic demand.

${ }^{*}$ Corresponding author. Department of Economics, University of Iowa, Iowa City, IA 52242-1994, USA. E-mail: rabah-amir@uiowa.edu . WWW: https://tippie.uiowa.edu/people/rabah-amir .

** Department of Economics, University of Manchester, Oxford Road, M13 9PL, UK. E-mail: igor.evstigneev@manchester.ac.uk. WWW: http://www.evstigneev.net. 


\section{Introduction}

Although written in the form of a book review, Bertrand's (1883) critique of Cournot's (1838) oligopoly turned out to form the most widely used model of price competition. Indeed, nowadays, the Bertrand duopoly model is one of the cornerstones of introductory microeconomics and game theory. The "Bertrand paradox" usually refers to the unusual equilibrium outcome of perfect competition in a market with just two firms 1 The strategies whose implementation leads to this outcome prescribe to set the minimal prices (equal to the marginal costs), resulting in zero profits. The fact that such strategies form a Nash equilibrium is a simple observation, and actually does not require any assumptions on the model. However, uniqueness holds only under additional assumptions, and its proof requires some quite elementary but novel arguments.

To the best of our knowledge, the literature provides no necessary and sufficient conditions for the uniqueness of a pure-strategy Bertrand-Nash equilibrium. In the present note, we formulate such a condition in terms of static collusion being unsustainable, an intuitive assumption. In addition, we also provide easily verified sufficient conditions for this key assumption in terms of standard properties of demand. This finding seems to be the first result of this kind after more than a century of studies on the Bertrand duopoly model and its versions.

Owing to a number of special game-theoretic features, the classical Bertrand duopoly has generated broad interest extending far beyond oligopoly theory and modern industrial organization. The first feature of interest is that the Bertrand game is the oldest representative of the class of classical games with naturally discontinuous payoff functions? 2 In addition, the payoff discontinuity along the price diagonal is extreme: the low-priced firm grabs the entire market and the rival gets nothing. 3 Another key feature of the classical

\footnotetext{
${ }^{1}$ It is well known that the Bertrand paradox is in many ways not very robust. For the case of convex costs, see Dastidar (1995). For the Bertrand-Edgeworth version with unequal unit costs, see Deneckere and Kovenock (1996). For product differentiation and endogenous timing, see Amir and Stepanova (2006).

${ }^{2}$ The payoff functions are not even upper semi-continuous in the prices, so the firms' reaction curves are not well defined. Thus the Bertrand duopoly does not fit the usual classes of games with discontinuous payoffs (Reny, 2016). In addition, the payoffs are not quasi-concave in own action, so the results from that literature do not apply. Nonetheless, an exception is Prokopovych and Yannelis (2017), who derive a general result that includes existence in the Bertrand model as a special case.

${ }^{3}$ As a consequence, the Bertrand game belongs to a family of games for which a tie breaking rule is a
} 
Bertrand game is that the unique Nash equilibrium is in weakly dominated strategies. Indeed, pricing at marginal cost yields zero profit to the two firms. Finally, the Nash equilibrium payoffs correspond to the individually rational payoffs of the firms, or their maxmin payoffs, which makes the infinitely repeated version of the game a convenient and robust model for studying tacit collusion via the Folk Theorem.

A key reason the Bertrand model has generated broad interest beyond oligopoly theory is the fact that other, a priori unrelated, games in experimental economics and game theory turned out to share these properties in one form or another. These games include the Guess-The-Average game (Moulin, 1986), which, along with various extensions, has spurned an extensive literature in experimental economics, see e.g. Nagel, Bühren, and Björn (2017). This is a constant-sum game wherein players pick numbers in $[0,100]$ and the one closest to $2 / 3$ of the average wins a fixed prize (with ties sharing the prize equally), and the others get 0 . In the two-player version, 0 is also a weakly dominant strategy (Grosskopf and Nagel, 2006). The unique Nash equilibrium, which calls for every player to pick 0, garnered little support in laboratory experiments, although play unraveled towards it. Yet, a discretized and stylized version of the Bertrand game confirmed the usual equilibrium, more so with more than two players (Dufwenberg and Gneezy, 2000).

Although pertaining to a different social situation, the Traveler's Dilemma (Basu, 1994) has a similar structure, with the key modification that the value of "undercutting the rival" is smoothed out to a small reward, in contrast to the extreme gap characterizing the other two games. Although the Nash equilibrium calls for the players to pick the lowest number and share the prize, laboratory behavior displayed significant departures from this robust theoretical prediction (Capra, Goeree, Gomez, and Holt, 1999).

One possible implication of the present study of Bertrand duopoly is that it might shed some light towards a systematic study of the aforementioned general class of games and their variants. Another interesting implication is that the downwards monotonicity of the demand function is not relevant to the existence or uniqueness of the BertrandNash equilibrium (we shall return to this point below). As a final remark, it is worth noting that, by offering a complete characterization of uniqueness of Nash equilibrium, our elementary result has no antecedents in game theory, in that uniqueness is typically guaranteed with sufficient conditions that are often quite far from necessary. Indeed, necessary part of the definition of the game, and its specification is often a critical part of its solution. 
uniqueness almost invariably follows from a global contraction-type argument.

\section{The main result}

We consider a version of the Bertrand duopoly model with a homogeneous product. There are two profit-maximizing firms 1 and 2 producing a homogeneous good in a market whose demand function is given by $D(p) \geq 0(p \geq 0)$. The cost, $c \geq 0$, per unit produced is the same for both firms. The firms simultaneously set their prices $p_{1}$ and $p_{2}$. Sales for firm $i$ are then given by

$$
D_{i}\left(p_{1}, p_{2}\right)=\left\{\begin{array}{cl}
D\left(p_{i}\right), & \text { if } p_{i}<p_{j} \\
\frac{1}{2} D\left(p_{i}\right), & \text { if } p_{i}=p_{j} \\
0, & \text { if } p_{i}>p_{j}
\end{array}\right.
$$

The firms' profit functions are

$$
\pi_{i}\left(p_{1}, p_{2}\right)=\left(p_{i}-c\right) D_{i}\left(p_{1}, p_{2}\right), i=1,2
$$

We assume that the firms never set prices that are less than $c$ : if $p_{i}<c$, then firm $i$ cannot have a strictly positive profit $\pi_{i}>0$. Thus we have a game with payoffs $\pi_{1}\left(p_{1}, p_{2}\right), \pi_{2}\left(p_{1}, p_{2}\right)$ and the strategy set $P_{c}=[c, \infty)$ for both players. The game is symmetric: $\pi_{2}\left(p_{1}, p_{2}\right)=\pi_{1}\left(p_{2}, p_{1}\right)$.

Since we consider only those prices $p_{i}$ that satisfy $p_{i} \geq c$, it is sufficient to assume that $D(p)$ is defined only for $p \geq c$.

We are interested in (pure-strategy) Nash equilibria of the above game (Bertrand-Nash equilibria), i.e., pairs of prices $\left(p_{1}^{*}, p_{2}^{*}\right), p_{i}^{*} \geq c$, such that

$$
\pi_{1}\left(p_{1}^{*}, p_{2}^{*}\right) \geq \pi_{1}\left(p_{1}, p_{2}^{*}\right) \text { and } \pi_{2}\left(p_{1}^{*}, p_{2}^{*}\right) \geq \pi_{2}\left(p_{1}^{*}, p_{2}\right)
$$

for all $p_{1}, p_{2} \geq c$.

The next result is well-known (though note the abscence of the usual assumptions).

Theorem 1. The prices

$$
p_{1}^{*}=p_{2}^{*}=c
$$

form a symmetric Nash equilibrium in the Bertrand game. 
Proof. Since the game is symmetric, it is sufficient to prove that $\pi_{1}(p, c) \leq \pi_{1}(c, c)$ for every $p \geq c$. We have $\pi_{1}(c, c)=0$. If $p>c$, then $\pi_{1}(p, c)=(p-c) D_{1}(p, c)=(p-c) \cdot 0=$ $\pi_{1}(c, c)$, which completes the proof.

We provide a criterion for the uniqueness of equilibrium in the Bertrand duopoly model. Denote by $\pi(p)$ the monopoly profit

$$
\pi(p)=(p-c) D(p)
$$

that the firm gets by setting the price $p$ and serving the entire demand $D(p)$ alone.

For the uniqueness result, we shall need the following simple and intuitive condition: (D) For each $p>c$, there exists $q=r(p)$ such that $c<q<p$ and

$$
\pi(q)>\pi(p) / 2
$$

This condition means that, given a price $p$, by setting some price $q=r(p)$ below $p$, the firm can get a profit $\pi(q)$ higher than half of the monopoly profit at price $p$, i.e., $\pi(p)$. An interesting interpretation of this condition is that it ensures that static collusion between the two firms in the form of equal market sharing at any price $p$ is not sustainable, in that each firm has a profitable deviation $q 4^{4}$ This is a very mild assumption, as will be seen through two easy-to-check sufficient conditions we provide for it below.

Theorem 2. Condition (D) is necessary and sufficient for $(c, c)$ to be the only Nash equilibrium in the Bertrand duopoly.

Proof. Let (D) hold. Suppose there is another Nash equilibrium, $\left(p_{1}, p_{2}\right), p_{i} \geq c$, distinct from $(c, c)$. We may assume without loss of generality that $p_{1} \leq p_{2}$ (one can always swap $p_{1}$ and $p_{2}$ ).

We consider three cases, in all of which we arrive at a contradiction with the assumption that $\left(p_{1}, p_{2}\right)$ is a Nash equilibrium.

1st case: $c<p_{1}<p_{2}$. Observe that $D\left(p_{1}\right)>0$. Indeed, if $D\left(p_{1}\right)=0$, then firm 1 can replace the price $p_{1}$ by the price $q=r\left(p_{1}\right)<p_{1}$ described in (D), which will lead to a strict increase in its profit

$$
(q-c) D(q)>\left(p_{1}-c\right) D\left(p_{1}\right) / 2=0
$$

\footnotetext{
${ }^{4}$ In other words, this assumption is minimally needed to validate the standard repeated games approach to the study of collusion under price competition (see e.g., Tirole, 1988, Chap. 6).
} 
But this is impossible as long as $\left(p_{1}, p_{2}\right)$ is a Nash equilibrium.

Here the profit of firm 2 is zero (since $p_{1}<p_{2}$ ). Therefore by setting the price $p_{1}$ instead of $p_{2}$, it can get a strictly positive profit

$$
\pi_{2}\left(p_{1}, p_{1}\right)=\left(p_{1}-c\right) D\left(p_{1}\right) / 2>0
$$

Consequently, $\left(p_{1}, p_{2}\right)$ is not a Nash equilibrium.

2nd case: $c=p_{1}<p_{2}$. Then firm 1's profit is zero, and it can obtain, by setting instead of the price $p_{1}=c$ the price $q=r\left(p_{2}\right)<p_{2}$ (see condition (D)), a strictly positive profit:

$$
\pi_{1}\left(q, p_{2}\right)=(q-c) D(q)>\left(p_{2}-c\right) D\left(p_{2}\right) / 2 \geq 0
$$

Therefore $\left(p_{1}, p_{2}\right)$ is not a Nash equilibrium.

3rd case: $c<p_{1}=p_{2}$. By virtue of (D), there exists a price $q=r\left(p_{1}\right)<p_{1}$ such that

$$
(q-c) D(q)>\left(p_{1}-c\right) D\left(p_{1}\right) / 2=\pi_{1}\left(p_{1}, p_{2}\right)
$$

This means that firm 1 can increase its profit by charging the price $q$ instead of $p_{1}$, which contradicts the assumption that $\left(p_{1}, p_{2}\right)$ is Nash equilibrium.

Thus we have proved that condition (D) is sufficient for the uniqueness of Nash equilibrium in Bertrand duopoly. Let us prove that this condition is also necessary. Suppose (D) does not hold. This means that for some $\bar{p}>c$, the inequality

$$
(q-c) D(q) \leq(\bar{p}-c) D(\bar{p}) / 2
$$

is satisfied for all $c<q<\bar{p}$. We claim that $(\bar{p}, \bar{p})$ is a Nash equilibrium, i.e., each firm, deviating unilaterally from $\bar{p}$ cannot strictly increase its profit. Indeed, if it sets a price $q>\bar{p}$, then its profit is zero. If it sets a price $c<q<\bar{p}$, its profit cannot be greater than $(\bar{p}-c) D(\bar{p}) / 2$ by virtue of (1), and the same is true of course if $q=c$.

The proof is complete.

\section{Sufficient conditions}

We now provide familiar sufficient conditions on the demand function for the uniqueness of a Bertrand-Nash equilibrium $5^{5}$ Consider the following alternative assumptions:

\footnotetext{
${ }^{5}$ With unbounded demand, Baye and Morgan (1999) identify mixed-strategy equilibria even under the usual assumptions.
} 
(D1) The function $D(p)$ is continuous on $[c, \infty)$, and $D(c)>0$.

(D2) The function $D(p)$ is non-increasing on $[c, \infty)$, and there exists $p^{*}>c$ such that $D\left(p^{*}\right)>0$.

In most textbook treatments of Bertrand duopoly, (D1) and (D2) are assumed together, along with the presence of a choke-off price $p_{0}$ such that $D\left(p_{0}\right)=0$ (Mas-Colell et. al. 1995, p. 388). In textbooks on industrial organization, these assumptions are often not explicitly listed, but one can infer from the context that the tacit assumptions on demand are the same: continuity and downward-monotonicity (Tirole, 1988).

We now show that either of (D1) and (D2) is sufficient for our assumption (D) to hold.

Theorem 3. Each of the assumptions (D1) and (D2) implies (D).

Proof. Let (D1) hold. Consider any $p>c$. We have either $D(p)=0$ or $D(p)>0$. If $D(p)=0$, take any $q>c$ sufficiently close to $c$ for which $D(q)>0$ ( $q$ exists by virtue of the continuity of $D(p))$. Then

$$
\pi(q)=(q-c) D(q)>0=(p-c) D(p) / 2=\pi(p) / 2 .
$$

If $D(p)>0$, then $(p-c) D(p)>0$, and since $D(p)$ is continuous, we have

$$
(q-c) D(q)>(p-c) D(p) / 2
$$

for all $q<p$ close enough to $p$. Thus we have proved that (D1) implies (D).

Suppose (D2) holds. Let $p>c$. If $D(p)=0$, then $p>p^{*}$ because $D(\cdot)$ is a nonincreasing function and $D\left(p^{*}\right)>0$. We can define $q=r(p)$ as $p^{*}$. Indeed,

$$
\pi(q)=\left(p^{*}-c\right) D\left(p^{*}\right)>0=(p-c) D(p) / 2=\pi(p) / 2 .
$$

Let $D(p)>0$. Define $q=r(p)$ as any number satisfying $(p+c) / 2<q<p$. Then we have

$$
\pi(q)=(q-c) D(q)>\frac{p-c}{2} D(p)=\pi(p) / 2
$$

because $q-c>(p+c) / 2-c=(p-c) / 2$ and $D(q) \geq D(p)>0$.

The proof is complete.

It is worth recalling that industrial organization deviated from standard microeconomics early on by postulating a downward-sloping demand as a primitive. To ensure 
that a demand function derived from the maximization of a utility (subject to a budget constraint) is decreasing, one needs the somewhat restrictive assumption of a quasi-linear utility in a numeraire good (e.g., Amir et. al, 2017 or Vives, 2000). Alternative approaches in microeconomics that were not adopted in industrial organization include the theory of demand aggregation (Grandmont, 1992 and Hildenbrand, 1994), a Marshallian notion of small income effects (Vives, 1987), and imposing restrictive sufficient conditions on the standard consumer problem (e.g., Quah, 2007). Given this dichotomy between industrial organization and the broader microeconomics field, there is some theoretical motivation for developing results in oligopoly theory that do not rely on a downward-sloping demand as a primitive. The present note may thus be seen as a step in this direction.

\section{REFERENCES}

Amir, R., Erickson, P., Jin, J., 2017. On the microeconomic foundations of linear demand for differentiated products, J. Econ. Theory 169, 641-665.

Amir, R., Stepanova, A., 2006. Second-mover advantage and price leadership in Bertrand duopoly, Games Econ. Behav. 55, 1-20.

Basu, K., 1994. The Traveler's Dilemma: Paradoxes of rationality in game theory. Amer. Econ. Rev. 84, 391-395.

Baye, M.R., J Morgan, 1999. A folk theorem for one-shot Bertrand games. Econ. Letters, 65, 59-65.

Baye, M.R., J Morgan, 2002. Winner-take-all price competition, Econ. Theory, 19, $271-282$.

Bertrand, J.L.F., 1883. Compte-rendu de Théorie de la richesse sociale par Léon Walras et de Recherches sur les principes mathématiques de la théorie des richesses par Augustin Cournot. Journal des Savants 67, 499-508.

Capra, C.M., Goeree, J.K., Gomez, R., Holt, C.A., 1999. Anomalous behavior in a traveler's dilemma?, Amer. Econ. Rev. 89, 678-690. 
Cournot, A., 1838. Recherches sur les Principes Mathématiques de la Théorie des Richesses. Hachette Livre, Paris.

Dastidar, K.G., 1995. On the existence of pure strategy Bertrand equilibrium, Econ. Theory, 5, 19-32.

Deneckere, R.J. and Kovenock, D., 1996. Bertrand-Edgeworth duopoly with unit cost asymmetry. Econ. Theory 8, 1-25.

Dufwenberg, M and Gneezy, U., 2000. Price competition and market concentration: an experimental study, Int. J. Ind. Organ. 18, 7-22.

Grandmont, J.-M., 1992. Transformations of the commodity space, behavioral heterogeneity, and the aggregation problem, J. Econ. Theory, 57, 1-35.

Grosskopf, B., Nagel, R., 2006. The two-person beauty contest, Games Econ. Behav. 62, 93-99.

Hildenbrand, W., 1994. Market Demand: Theory and Empirical Evidence, Princeton University Press, Princeton, N.J.

Mas-Colell, A., Whinston, M.D., and Green, J.R., 1995. Microeconomic Theory. Oxford University Press, Oxford, U.K.

Moulin, H., 1986. Game Theory for Social Sciences. New York University Press, N. Y.

Nagel, R., Bühren, C., and Björn, F., 2017. Inspired and inspiring: Hervé Moulin and the discovery of the beauty contest game. Math. Soc. Sci., 90, 191-207.

Prokopovych, P., and Yannelis, N.C., 2017. On strategic complementarities in discontinuous games with totally ordered strategies. J. Math. Econ., 70, 147-153.

Quah, J. K., 2003. The Law of demand and risk aversion, Econometrica, 71, 2, 713-721.

Reny, P. J., 2016. Introduction to the symposium on discontinuous games. Econ. Theory $61,423-429$.

Tirole, J., 1988. The Theory of Industrial Organization. MIT Press, Cambridge, MA. 
Vives, X., 1987. Small income effects: A Marshallian theory of consumer surplus and downward sloping demand. Rev. Econ. Stud. 54, 87-103.

Vives, X., 2000. Oligopoly Pricing: Old Ideas and New Tools. MIT Press, Cambridge. 